\title{
Comparison between Preterm versus Full Term Septic Neonates Whose Feeding Is Powdered Milk Formula Regarding Cronabacter Sakazakii
}

Abdelrazek Hefny Elsheikh ${ }^{1}$, Ehab Abdelmoneim Elbanaa ${ }^{1}$, Ahmed Shahin ${ }^{2}$, Ahmed Alaa Eldein Gameel*1

Departments of ${ }^{1}$ Pediatrics and ${ }^{2}$ Microbiology and Immunology, Faculty of Medicine, Zagazig University, Egypt

*Corresponding Author: Ahmed Alaa Eldein Gameel, Email: ahmedalaaeldeenn@ gmail.com

\begin{abstract}
Background: Foodborne pathogen Cronobacter sakazakii (CS) has been detected around the world. When it comes to foodborne bacteria, C. difficile (CS) is one of the most prevalent diseases, particularly among infants with low birth weight and preterm neonates.

Objective: To compare between the incidence of Cronobacter Sakazakii infection among preterm versus full term septic neonates whose feeding is powdered milk formula.

Patients and Methods: Our study was a comparative cross-sectional study and included 50 neonates: 25 full term and 25 premature. It was conducted at Pediatrics Department, Zagazig University Hospital and the patients' status fulfilled the inclusion and exclusion criteria. Medical history, clinical examination, and laboratory tests were performed on all patients. Collection of specimens and culture and sensitivity tests for the isolates were also done. Results: There was significant increase of prevalence of Cronobacter sakazakii in preterm more than full term. The sepsis score and its associated characteristics varied significantly between the two groups. With time, increasing temperature led to reduce number of $\mathrm{C}$. sakazakii in reconstituted infant powdered milk

Conclusion: Powdered infant formula (PIF) can be contaminated with C. sakazakii, which can cause sickness in infants who are fed PIF rather than breast milk, and in preterm infants rather than full-term ones.
\end{abstract}

Keywords: Cronobacter sakazakii, Powdered Milk Formula, Preterm.

\section{INTRODUCTION}

One of the members of the Enterobacteraceae family, Cronobacter is also known as Enterobacter sakazakii. Non-spore, rod-shaped, and peritrichous flagella producing bacteria are the characteristics of Cronobacter. It is Gram-negative bacterium. Citrobacter and Enterobacter are closely related to this bacterium. A wide range of food products, including powdered infant formula (PFI), have been shown to contain Cronobacter spp., including spices, wheat, herbs and rice ${ }^{(\mathbf{1})}$.

Foodborne pathogen Cronobacter sakazakii has been detected around the world. Plant-based beverages and foods, vegetables, PIF, fruits, cereals and other plant-based foodstuffs all include it. Because PIF is a non-sterilized product, contamination is more likely to occur $^{(2)}$.

Cronobacter's epidemiology and virulence are both poorly understood at this time. However, because reconstituted PIF is commonly provided to neonates (particularly those in neonatal critical care units), this product has drawn attention for its ability to reduce infection risk in newborns due to the limited number of exposure pathways ${ }^{(3)}$.

There are many ways in which the opportunistic pathogen CS might infect a host. Adults are more likely than children to contract Cronobacter infections, which affect all age groups. Preterm infants, immunocompromised newborns and neonates with low birth weight (LBW), are the most often known groups at risk because the bacteria cause necrotizing enterocolitis (NEC), meningitis and sepsis in hospitalized neonates ${ }^{(4)}$.

Listeria monocytogenes and Clostridium botulinum are two of the most frequent bacterial diseases and CS has been put in this group. As with Salmonella, CS is becoming more and more of a cause for concern when it comes to foodborne bacteria. PIF reconstituted under favorable conditions could allow this bacterium to multiply and pose a major threat, as researchers have discovered ${ }^{(5)}$.

We aimed at this study to compare between the incidence of Cronobacter sakazakii infection among preterm versus full term septic neonates whose feeding is powdered milk formula.

\section{PATIENTS AND METHODS}

The study was a comparative cross-sectional trial that included 50 neonates: 25 full term and 25 premature and was carried out at the Newborn Intensive Care Unit (NICU) of the Pediatrics Department, Zagazig University Hospital.

\section{Ethical considerations:}

As long as all parents of participants signed informed consent forms and submitted them to Zagazig University's research ethics committee, the study was 
allowed (ZU-IRB\#6681). We followed the World Medical Association's ethical code for human experimentation, the Helsinki Declaration.

\section{Inclusion criteria:}

Neonates from both sexes with proven sepsis based on clinical and laboratory evidence, whose feeding was powdered milk formula, considering low birth weight is less than 2,500 grams while babies weighing less 1,500 at birth were considered very low birth weight ${ }^{(\boldsymbol{6})}$.

\section{Exclusion criteria:}

Babies more than four weeks, neonates without sepsis, Neonates whose feeding was breast milk feeding or who had CNS or congenital problems.

Patients were classified into two groups: Group 1: Preterm neonates (25 proven sepsis patients), and Group 2: Full term neonate (25 proven sepsis patients).

\section{This is what all of the participants in this research had to go through:}

1. History taking and clinical examination.

2. Gestational age assessment via the Ballard Score (7) and Apgar score was also assessed ${ }^{(8)}$.

3. Full clinical examination for all systems (e.g. respiratory, cardiovascular, neurological, gastrointestinal system): We collected vital data for each patient especially general condition, blood pressure, body temperature, respiratory rate, heart rate, weight, length, as well as body mass index. We completed physical examination with stress on clinical features of sepsis that demonstrates the sepsis score and other critical data as poor oral intake, fever $>37.8^{\circ} \mathrm{C}$, hypothermia $<36^{\circ} \mathrm{C} \%$, jaundice, seizures, eye discharge, skin rashes, respiratory distress, apnea, pneumonia, or diarrhea ${ }^{(9)}$.

4. Laboratory investigations: involving, ESR, complete blood count, CRP, ABG, etc. according to FDA guidelines, Cronobacter sakazakii was isolated ${ }^{(\mathbf{1 0})}$.

\section{Statistical analysis}

In order to analyse the data acquired, it was loaded into a computer and run via the Statistical Package for the Social Sciences, version 25. (SPSS). Tables were used to present the findings. The quantitative data were reported in the form of the mean and standard deviation. The frequency and proportions were used to present qualitative data. For quantitative independent data, the student's t test (T) was used. To examine qualitatively independent data, researchers employed the Pearson Chi-Square $\left(\chi^{2}\right)$ test. Significance of the obtained results was judged at the 5\% level.

\section{RESULTS}

Table 1 shows that there was insignificant difference between both groups as regard gender, type of delivery, 5 minutes Apgar, maternal age, maternal parity and gestational age. 
Table (1): Demographic characteristics, between the studied groups

\begin{tabular}{|c|c|c|c|}
\hline Character & Preterm $(\mathrm{N}=25)$ & Full-Term $(\mathrm{N}=25)$ & P value \\
\hline $\begin{array}{l}\text { Gender: } \\
\text { Male \% (n) } \\
\text { Female \% (n) }\end{array}$ & $\begin{array}{c}68 \%(17) \\
32 \%(8)\end{array}$ & $\begin{array}{c}72 \%(18) \\
28 \%(7)\end{array}$ & 0.75 \\
\hline $\begin{array}{l}\text { Residence: } \\
\text { Rural \% (n) } \\
\text { Urban \% (n) }\end{array}$ & $\begin{array}{c}68 \%(17) \\
32 \%(8)\end{array}$ & $\begin{array}{c}76 \%(19) \\
24 \%(6)\end{array}$ & 0.52 \\
\hline $\begin{array}{l}\text { Type of delivery: } \\
\text { NVD \% (n) } \\
\text { C/S \% (n) }\end{array}$ & $\begin{array}{c}28 \%(7) \\
72 \%(18)\end{array}$ & $\begin{array}{l}52 \%(13) \\
48 \%(12)\end{array}$ & 0.08 \\
\hline $\begin{array}{l}5 \text { minutes Apgar Score: } \\
0-3(n) \\
4-6(n) \\
7-10(n)\end{array}$ & $\begin{array}{c}6 \\
8 \\
11 \\
\end{array}$ & $\begin{array}{c}4 \\
9 \\
12 \\
\end{array}$ & 0.77 \\
\hline $\begin{array}{l}\text { Maternal Age (years): } \\
<20(\mathrm{n}) \\
20-30(\mathrm{n}) \\
>30(\mathrm{n})\end{array}$ & $\begin{array}{c}7 \\
12 \\
6\end{array}$ & $\begin{array}{c}3 \\
20 \\
2 \\
\end{array}$ & 0.06 \\
\hline $\begin{array}{l}\text { Maternal Parity: } \\
1-2(\mathrm{n}) \\
2-4(\mathrm{n}) \\
>4(\mathrm{n})\end{array}$ & $\begin{array}{l}8 \\
8 \\
9 \\
\end{array}$ & $\begin{array}{l}13 \\
10 \\
2 \\
\end{array}$ & 0.05 \\
\hline $\begin{array}{l}\text { Gestational age: } \\
\text { Extremely <28 } \\
\text { Very preterm } 28-32 \\
\text { Moderate } 32-34 \\
\text { Late } 34-36 \\
\end{array}$ & $\begin{array}{l}- \\
- \\
- \\
-\end{array}$ & $\begin{array}{l}48 \%(12) \\
28 \%(7) \\
8 \%(2) \\
16 \%(4) \\
\end{array}$ & 0.52 \\
\hline
\end{tabular}

Table 2 shows that there was insignificant difference between both groups as regard clinical manifestations.

Table (2): Clinical manifestations of studied cases

\begin{tabular}{|l|c|c|c|}
\hline Clinical manifestations & $\begin{array}{c}\text { Preterm } \\
\text { (N=25) }\end{array}$ & Full-Term (N=25) & P value \\
\hline Refusal of feeding \% (n) & $76 \%(19)$ & $56 \%(14)$ & \\
Fever>37.8 $8^{\circ} \mathrm{C}(\mathrm{n})$ & $88 \%(22)$ & $80 \%(20)$ & \\
Hypothermia <36 \% (n) & $20 \%(5)$ & $12 \%(3)$ & \\
Jaundice \% (n) & $32 \%(8)$ & $28 \%(7)$ & $>0.05$ \\
Seizures \% (n) & $8 \%(2)$ & $4 \%(1)$ & \\
Eye Discharge \% (n) & $12 \%(3)$ & $12 \%(3)$ & \\
Skin Rash \% (n) & $12 \%(3)$ & $8 \%(2)$ & \\
Respiratory Distress \% (n) & $88 \%(22)$ & $76 \%(19)$ & \\
Apnea \% (n) & $20 \%(5)$ & $16 \%(4)$ & \\
Pneumonia \% (n) & $32 \%(8)$ & $20 \%(5)$ & \\
Diarrhea \% (n) & $28 \%(7)$ & $32 \%(8)$ & \\
\hline
\end{tabular}

Table 3 shows that there was significant increase of prevalence of Cronobacter sakazakii in preterm more than full term.

Table (3): Cronobacter sakazakii in the studied groups in PIF

\begin{tabular}{|l|c|c|c|}
\hline \multicolumn{1}{|c|}{ Variables } & Preterm & Full-Term & \multirow{2}{*}{ P-value } \\
\hline Cronobacter sakazakii & & & \multirow{2}{*}{0.016} \\
\hline Positive & 9 & 2 & \\
\hline Negative & 16 & 23 & \\
\hline
\end{tabular}

Table 4 shows that there was a significant difference in sepsis score between the two groups and its parameters. 
Table (4): Sepsis score and sepsis score parameters in the studied groups

\begin{tabular}{|l|c|c|c|}
\hline \multicolumn{1}{|c|}{ Sepsis score } & Preterm & Full-Term & P value \\
\hline WBCs count & 13 & 10 & 0.05 \\
$<5000$ & 12 & 15 & \\
$>25000$ & 3 & 2 & $<0.05$ \\
\hline PMN count & 3 & 0 & \\
Increased/Decreased & 15 & 10 & $<0.05$ \\
No mature & 5 & 2 & $<0.05$ \\
\hline Immature PMN count & 6 & 2 & 0.05 \\
Increased & 5 & 2 & $<0.05$ \\
I/N PMN ratio (increased) & 7 & 5 & $<0.05$ \\
I/M PMN ratio (>0.3) & & & \\
Degenerative changes in PMN & $5.5(2.3)$ & $2.1(1.1)$ & \\
\hline Platelet & \multicolumn{2}{|}{} \\
$<150000$ & & & \\
\hline Sepsis score & & & \\
Mean \pm SD & & & \\
\hline
\end{tabular}

Table 5 shows that detected gene in Cronobacter sakazakii LMG 2789 LMG was 28141, detected Cronobacter sakazakii DSM 4485T DSM was 28141, and detected Cronobacter sakazakii DSM 4485T DSM was 28141. There was non-significant difference between refrigeration and ambient temperature storage as regard storage duration. There was insignificant difference in number of colonies of C. sakazakii after opening box.

Table (5): C. sakazakii biotyper database based on the samples analysed (PIF), Count of C. sakazakii in reconstituted infant powdered milk at refrigeration and ambient temperature storage (Mean \pm Standard Deviation)

\begin{tabular}{|c|c|c|c|}
\hline $\begin{array}{c}\text { National Center for } \\
\text { Biotechnology Information } \\
\text { Identifier }\end{array}$ & Score & \multicolumn{2}{|c|}{ Strain } \\
\hline 28141 & 2.032 & \multicolumn{2}{|c|}{ Cronobacter sakazakii LMG 2789 LMG } \\
\hline 28141 & 2.166 & \multicolumn{2}{|c|}{ Cronobacter sakazakii DSM 4485T DSM } \\
\hline 28141 & 2.158 & \multicolumn{2}{|c|}{ Cronobacter sakazakii DSM 4485T DSM } \\
\hline \multirow[t]{2}{*}{ Storage duration (hour) } & \multicolumn{2}{|c|}{ Number of C. sakazakii (CFU/mL) } & \multirow[t]{2}{*}{ P value } \\
\hline & $\begin{array}{c}\text { Refrigeration } \\
\text { temperature }\end{array}$ & $\begin{array}{c}\text { Ambient } \\
\text { temperature }\end{array}$ & \\
\hline 4 & $5.1771 \pm 0.0001$ & $5.1770 \pm 0.0003$ & \multirow{6}{*}{$>0.05$} \\
\hline 8 & $5.1778 \pm 0.0002$ & $5.1780 \pm 0.0002$ & \\
\hline 24 & $5.1779 \pm 0.001$ & $6.8333 \pm 0.013$ & \\
\hline 48 & $5.1782 \pm 0.001$ & $7.0156 \pm 0.006$ & \\
\hline 72 & $5.1793 \pm 0.0003$ & $7.2793 \pm 0.02$ & \\
\hline 96 & $5.1793 \pm 0.0004$ & $7.3214 \pm 0.007$ & \\
\hline
\end{tabular}

Table 6 shows that with time, increasing temperature led to reduce number of C. sakazakii in reconstituted infant powdered milk.

Table (6): Count of surviving heat resistant C. sakazakii at temperatures $54^{\circ} \mathrm{C}$ to $64^{\circ} \mathrm{C}$ in reconstituted infant powdered milk (Mean \pm Standard Deviation)

\begin{tabular}{|l|c|c|c|c|c|}
\hline Time & $\mathbf{5 4}^{\circ} \mathbf{C}$ & $\mathbf{5 6}^{\circ} \mathbf{C}$ & $\mathbf{5 8}^{\circ} \mathbf{C}$ & $\mathbf{6 0}^{\circ} \mathbf{C}$ & $\mathbf{6 4}^{\circ} \mathbf{C}$ \\
\hline 0 & $8.191 \pm 0.002$ & $8.193 \pm 0.0004$ & $8.198 \pm 0.003$ & $8.199 \pm 0.005$ & $8.197 \pm 0.005$ \\
3 & $8.184 \pm 0.002$ & $8.192 \pm 0.001$ & $8.195 \pm 0.002$ & $8.175 \pm 0.002$ & $7.085 \pm 0.01$ \\
6 & $8.181 \pm 0.0003$ & $8.192 \pm 0.001$ & $8.178 \pm 0.001$ & $7.148 \pm 0.001$ & $7.012 \pm 0.01$ \\
9 & $8.164 \pm 0.01$ & $7.183 \pm 0.002$ & $7.175 \pm 0.002$ & $7.123 \pm 0.01$ & $6.125 \pm 0.01$ \\
12 & $7.173 \pm 0.001$ & $7.126 \pm 0.01$ & $7.167 \pm 0.001$ & $6.147 \pm 0.01$ & $5.115 \pm 0.01$ \\
15 & $7.172 \pm 0.0002$ & $7.112 \pm 0.002$ & $6.174 \pm 0.003$ & $6.115 \pm 0.002$ & $5.007 \pm 0.01$ \\
18 & $7.169 \pm 0.0001$ & $6.201 \pm 0.01$ & $6.149 \pm 0.004$ & $5.028 \pm 0.013$ & $4.179 \pm 0.01$ \\
\hline
\end{tabular}




\section{DISCUSSION}

Cronobacter, formerly known as Enterobacter sakazakii, is a genus of bacterium in the Enterobacteriaceae family. Citrobacter and Enterobacter are closely related to this bacterium. A wide range of food products, including powdered infant formula (PFI), have been shown to contain Cronobacter spp., including spices, wheat, herbs and rice ${ }^{(11)}$. According to Holy et al. ${ }^{(12)}$, little is known about this organism's epidemiology and virulence at this time. In spite of this, due to the restricted number of exposure routes, reconstituted powdered infant formula (PIF) has been the focus of effort for minimising infection risk to neonates.

One thing to keep in mind is that immunosuppressed people are more vulnerable to infections caused by opportunistic organisms such as C. sakazakii and salmonella, which are members of the Enterobacteriaceae family ${ }^{(\mathbf{1 3})}$.

Manufacturer conditions, as well as preparation and handling before consumption, are crucial since Cronobacter sakazakii cannot tolerate the temperatures at which milk is pasteurised but can be easily identified post-pasteurization. As a result, it is imperative that preventative measures be taken to remove or minimise the possibility of powdered infant formula (PIF) replication of the $\mathrm{C}$. sakazakii bacterium as well as its replication ${ }^{(\mathbf{1 4})}$.

Regarding the demographic data in our study, the majority of babies were males, and their residence was rural areas, maternal age from 20 to 30 years. There was no difference between the two groups regarding the clinical manifestations.

Salman and Naser ${ }^{(15)}$ showed that three prenatal risk factors were investigated in their study. The only factor which significantly appeared to increase the risk of C. sakazakii contamination of PIF was birth location. Six children $(37.5 \%)$ were positive for this bacterium had home delivery compared to only $15.47 \%$ of those which their formula was negative for this infection. Other prenatal factor (mode of delivery and gestational age) was far from significant.

This study showed that there was insignificant difference between both groups as regard gender, type of delivery, 5 minutes Apgar, maternal age, maternal parity or gestational age. Elkhawaga et al. ${ }^{(3)}$ showed that, in agreement with our results, there were $33.3 \%$ low Apgar score at 1 minute: 33.3 percent and low Apgar score at 5 minutes: 33.3 percent. Both preterm and term newborns who had five-minute Apgar scores from 0 to 3 as well as $\mathrm{pH}$ values that were less than 7 were more likely to die, according to Casey $\boldsymbol{e t}$ al. ${ }^{\left({ }^{(16)} \text {. }\right.}$ If babies with five-minute Apgar scores ranging from 0 to 3 and $\mathrm{pH}$ values of less than 7.0 were compared to those with Apgar scores ranging from 7 to 10 and $\mathrm{pH}$ values more than 7.0, the higher risk remained.

This study showed that there was significant increase of prevalence of Cronobacter sakazakii in preterm more than full term. Among the 100 patients of neonatal sepsis studied by Elkhawaga et al. (3), Cronobacter sakazakii was found in 12 of them. Herbs and water were also found to contain high concentrations of the microorganism in the range of 17.5, 9.2, and 7.5 percent.

Cronobacter sakazakii's transmission and infectious dosage remain unclear, according to Henry and Fouladkhah ${ }^{(17)}$. Cronobacter infections are extremely rare, however the number of instances that have been documented recently has grown modestly. The number of infections may be underestimated since not all clinical analysis laboratories do research on other bacterial pathogens and not all nations have a system for reporting diseases, even though there are fewer cases reported worldwide.

This study shows that detected gene in Cronobacter sakazakii LMG 2789 LMG was 28141, detected Cronobacter sakazakii DSM 4485T DSM was 28141, and detected Cronobacter sakazakii DSM 4485T DSM was 28141 .

Amer et al. ${ }^{(18)}$ found that three of the nine C. Sakazakii strains identified by biochemical testing technique MALDI-TOF were actually E. cloacae. MALDI-TOF analysis shows that only IFMP and Rice Pudding samples had C. sakazakii as an Enterobacteriaceae species, while infant food samples have the same percentages of various species with both of these samples.

This study shows that there was non-significant difference between refrigeration and ambient temperature storage as regard storage duration. With time, increasing temperature led to reduce number of bacteria. There were insignificant difference in number of colonies of $\mathrm{C}$. sakazakii after opening box. An investigation by Awadallah et al. ${ }^{(19)}$ found that infant powdered milk inoculum levels of $\mathrm{C}$. sakazakii (5.276 CFU/mL) persisted at the initial inoculum levels following incubation for 4, 8, 24, 48, 72, and 96 hours at $4^{\circ} \mathbf{C}$. There was no change in the number of colonies until 8 hours after inoculation at ambient temperature. After 24 hours, 48 hours, 72 hours, and 96 hours, there was a considerable rise. At 54, 56, 58, 60 , and $64^{\circ} \mathbf{C}, \mathrm{C}$. sakazakii D-values, which is the time in minutes at a given temperature to achieve a $90 \%$ reduction in the number of viable cells, were 13.79, $9.13,7.51,5.74$, and 4.64 minutes; the z-value, which is the number of degrees the temperature has to be increased to achieve a tenfold reduction in the D-value, was $17.42^{\circ} \mathbf{C}$.

Salman and Naser ${ }^{(15)}$ showed that molecular methods for detection C. sakazakii revealed positive amplification in 16 samples (16\%). Regarding prenatal risk factors results showed, six children $(37.5 \%)$ positive for this bacterium had home delivery compared to only $15.47 \%$ of those who were negative.

\section{CONCLUSION}

Powdered infant formula (PIF) can be contaminated with C. sakazakii, which can cause 
sickness in infants who are fed PIF rather than breast milk, and in preterm infants rather than full-term ones.

Financial support and sponsorship: Nil.

Conflict of interest: Nil.

\section{REFERENCES}

1. Enem S, Ogbu C, Okoli C et al. (2020): Detection and molecular characterization of Cronobacter sakazakii isolated from powdered infant formula (PIF) from North Central Region, Nigeria. Advances in Microbiology, 10(7): 307-317.

2. Fei P, Feng H, Wang Y et al. (2020): Amaranthus tricolor crude extract inhibits Cronobacter sakazakii isolated from powdered infant formula. Journal of Dairy Science, 103(11): 9969-9979.

3. Elkhawaga A, Hetta H, Osman $\mathrm{N}$ et al. (2020): Emergence of Cronobacter sakazakii in cases of neonatal sepsis in Upper Egypt: First Report in North Africa. Frontiers in Microbiology, 20: 1-11.

4. Jang H, Chase H, Gangiredla J et al. (2020): Analysis of the molecular diversity among Cronobacter species isolated from filth flies using targeted PCR, pan genomic DNA microarray, and whole genome sequencing analyses. Frontiers in Microbiology, 11: 2369-73.

5. Akineden Ö, Wittwer T, Geister K et al. (2020): Nucleic acid lateral flow immunoassay (NALFIA) with integrated DNA probe degradation for the rapid detection of Cronobacter sakazakii and Cronobacter malonaticus in powdered infant formula. Food Control, 109, 106952-56.

6. Basel P, Singh S (2020): Low birth weight and its associated risk factors: Health facility-based casecontrol study. PloS One, 15(6): 234907-11.

7. Stevenson A, Joolay Y, Levetan C et al. (2021): A Comparison of the accuracy of various methods of postnatal gestational age estimation; including Ballard score, foot length, vascularity of the anterior lens, last menstrual period and also a clinician's nonstructured assessment. Journal of Tropical Pediatrics, 67(1): 113-116.

8. Rudiger M, Rozycki H (2020): It's time to reevaluate the Apgar score. JAMA Pediatrics, 174(4): 321-322.

9. Odabasi O, Bulbul A (2020): Neonatal sepsis. The Medical Bulletin of Sisli Etfal Hospital, 54(2): 142147.
10. Mardaneh J, Soltan-Dallal M (2014): Isolation and identification of E. cowanii from powdered infant formula in NICU and determination of antimicrobial susceptibility of isolates. Iranian Journal of Pediatrics, 24(3): 261-266.

11. Lepuschitz S, Ruppitsch W, Pekard-Amenitsch S et al. (2019): Multicenter study of Cronobacter sakazakii infections in humans, Europe, 2017. Emerging Infectious Diseases, 25(3): 515-518.

12. Holy O, Cruz-Córdova A, Xicohtencatl-Cortes J et al. (2019): Occurrence of virulence factors in Cronobacter sakazakii and Cronobacter malonaticus originated from clinical samples. Microbial Pathogenesis, 127: 250-256.

13. Anvarinejad M, Pouladfar G, Pourabbas B et al. (2016): Detection of salmonella spp. With the BACTEC 9240 automated blood culture system in 2008-2014 in Southern Iran (Shiraz): biogrouping, MIC, and antimicrobial susceptibility profiles of isolates. Jundishapur Journal of Microbiology, 9(4): $1-4$.

14. Du X, Wang F, Lu X et al. (2012): Biochemical and genetic characteristics of Cronobacter sakazakii biofilm formation. Research in Microbiology, 163(67): 448-456.

15. Salman $J$, Naser $W$ (2018): Incidence of Cronobacter sakazakii in Iraqi infants with neonatal sepsis. Indian Journal of Public Health Research and Development, 9: 942-46.

16. Casey B, McIntire D, Leveno K (2001): The Continuing value of the Apgar score for the assessment of newborn infants. New England Journal of Medicine, 344(7): 467-471.

17. Henry M, Fouladkhah A (2019): Outbreak history, biofilm formation, and preventive measures for control of Cronobacter sakazakii in infant formula and infant care settings. Microorganisms, 7(3): 7781.

18. Amer I, Mansour M, Abdelfatah E et al. (2020): Cronobacter sakazakii and microbiological profile of infant formulae and some dairy products consumed by infants. Adv Anim Vet Sci., 8(3): 297-304.

19. Awadallah M, Ahmed H, Merwad A et al. (2018): Molecular characterization of Cronobacter sakazakii in Egypt, survival and thermoresistance at different temperatures: A potential public health risk. VectorBorne and Zoonotic Diseases, 18(2): 101-107. 